\title{
Modding and Rezzing in Games and Virtual Environments for Education
}

\author{
Regina Kaplan-Rakowski, M.Ed., M.A. \\ Dept. of Curriculum \& Instruction \\ Southern Illinois University Carbondale, IL 62901, USA \\ rkaplan@siu.edu
}

Christian Sebastian Loh, Ph.D.

Collaboratory for Interactive Learning Research (C.I.L.R.)

Southern Illinois University Carbondale, IL 62901, USA

csloh@siu.edu

\begin{abstract}
Creating new resources in computer games and virtual worlds by modification - also known as modding and rezzing, respectively - is a popular pastime activity of the new generation of learners. Educators need to understand the potentials of these activities for education, and to possibly integrate some of them into school curricula. This chapter provides an overview of the modification process to create new resources within a virtual environment (both games and virtual worlds). It examines the differences in the modification process between game worlds and virtual worlds, and offers practical considerations for using the activities in teaching and instruction.
\end{abstract}

\section{INTRODUCTION}

In this (post-)modern age, the Internet has become a venue for self-expression. Many online "venues," such as Blogger, Twitter, Second Life (SL), World of Warcraft (WoW), and YouTube, not only allow their users to express themselves in terms of thoughts, words, and actions but their business models depend on user-created and submitted materials in order to work. Despite their claims to be "online social services," Blogger, Craig's List, and Twitter are in effect World Wide Web (WWW) environments, or "spaces" that facilitate the establishment of virtual communities and online communications among them.

Specialized environments such as SL and WoW pushed the idea of community building even further by allowing their members to interact among virtual personifications of themselves (in the form of customizable avatars) within a traversable (virtual) environment. While the idea of a traversable three dimensional (3D) Internet might appear rather innovative to most users, it was not so for computer game players, who had experienced virtual environments (albeit a much simpler version), since the days of Pong and Space Commander.

Increasingly, social services, such as YouTube and Second Life, have become so dependent on usercreated materials, without which, the continuous existence of the sites could be at stake. Not surprisingly, user-created materials were prevalent in online and console games also. For example, the award winning LittleBigPlanet (for Sony PlayStation 3) allowed players to manipulate simple geometric shapes into more complex objects, and to modify or re-use these user-created objects for the construction of new 
game levels as peer-to-peer challenges. Serving as a virtual canvas, the online Blueprint Creator (available at http://www.littlebigworkshop.com/en-us/Tools/Blueprint) allowed players to put down their creative thoughts before trying to design new levels within the LittleBigPlanet online world.

Unlike the majority of the digital games in which players interacted with developer-made contents, the idea of: (1) allowing players to create new contents as a new way of 'play,' and (2) reusing the created contents for play by other players, was truly revolutionary. The levels of creativity and innovation skills, as well as information and communication technology literacy shown were all part of the 21st century skills that were deemed highly desirable in tomorrow's education (Partnership for $21^{\text {st }}$ Century Skills, 2006; available at http://www.21centuryskills.org). Educators and pundits alike have suggested that game modification could well become the new mode of learning in the future (see Becker \& Parker, 2005; Gee, 2008; Prensky, 2001, 2008). Given the history of game modification among the gamers' community, this is not surprising at all.

\section{GAME MODIFICATION}

The origin of game modification could be traced back to 1998, when the U.S. Marines first modified a commercial off-the-shelf (COTS) video game into a training game (from Doom to MarineDoom) (McLeroy, 2008). Over the years, game modification had grown to be another reason for buying/owning video games. Over the next few years, many video game modules have been constructed and distributed by gamers through various online channels. However, not all game modules were sanctioned by the game publishers; some might even be illegal (one example being the infamous Coffee Mod of Grand Theft Auto IV).

On the other hand, many game publishers were eager to support, and even encourage, the game modification process. A publisher's expressed support of the game modification process would usually be found in the form of a game development toolkit (GDK) that was distributed together with the game. Because GDKs were game specific, anyone interested in learning the game modification process had to tackle the game (and its corresponding GDK) on a one-to-one basis. Hence, the number of game modules available could be taken as an indicator for the size of the game modification community. By far, the largest game modification community was the Neverwinter Nights group, which has made available more than 5000 game modules since the game debuted in 2002.

The game modification process was a win-win situation for many parties involved. Researchers and educators have been known to take advantage of the GDKs in creating test-beds for innovative research (Gorniak \& Roy, 2005; Loh \& Byun, 2009; Young \& Nguyen, 2009), and in experimenting with new instructional approaches (Berger, 2006; Kafai, 2006; Squire, 2004). The game publishers benefitted directly from it because every module released by the user community would help to extend the shelf-life and sales of the product. Last but not least, gamers were delighted with the process because, not only could they customize the games to fit their gaming needs, they could further boast about their role as game designers.

\section{Machinima}

The debut of YouTube (http://www.youtube.com) in recent years has provided many independent amateur media producers with a voice. One interesting activity that had been spun off from game modification was that of digital film-making using a video game environment as a product set, or machinima - the word is a portmanteau of 'machine' and 'cinema.' By taking advantage of the real-time 3D virtual environments made possible only through video game technology (Lowood, 2008), more specifically through the GDKs, these media producers were able to tap into a near limitless number of actors and actresses without actually hiring anybody. 
Since the Massive Multi-players Online Games (MMOGs) became a worldwide phenomenon in the 2000s, there have been several machinima events in which large number of gamers were mobilized to congregate at a specific time and "place" within these virtual game environments to perform, en masse, certain acts for the purpose of machinima - including group dance, and even mass suicide (for the purpose of spelling out a particular message with the virtual bodies). Other media producers have alternatively taken advantage of the fantastic settings as inspiration for storytelling and for crafting epic adventures and film series from their home computers (see http://machinima.com/series/). Annual machinima exhibitions and online repositories (such as International Machinima Expo, and Machinima.com, respectively) have been created to further promote and expand the industry. Many of these activities had been almost unthinkable before the advent of game modification.

\section{Rezzing}

Even though it was once a pastime for teenagers and casual gamers, game modification has become a means for grown-ups and professionals to advance their own personal agendas. In the last five years, the game modification process has grown beyond the confines of video games, and had spilled over into other virtual environments, including virtual worlds such as Second Life (http://www.secondlife.com), There (http://www.there.com), and Active Worlds (http://www.activeworlds.com).

In its early years, virtual worlds functioned very much like 3D chat rooms, with the exception that each user could customize their own appearance (or avatar) within the application, and create virtual models of physical objects for display or manipulation. Conceptually, the ability to create models of physical objects using predisposed geometric models was highly similar to game modification. In Second Life (SL), for example, the denizens have opted for the term 'rezzing' (SL lingo) to describe their model making efforts (Figure 1, color version available at http://www.csloh.com/research/book_chapter_images/).

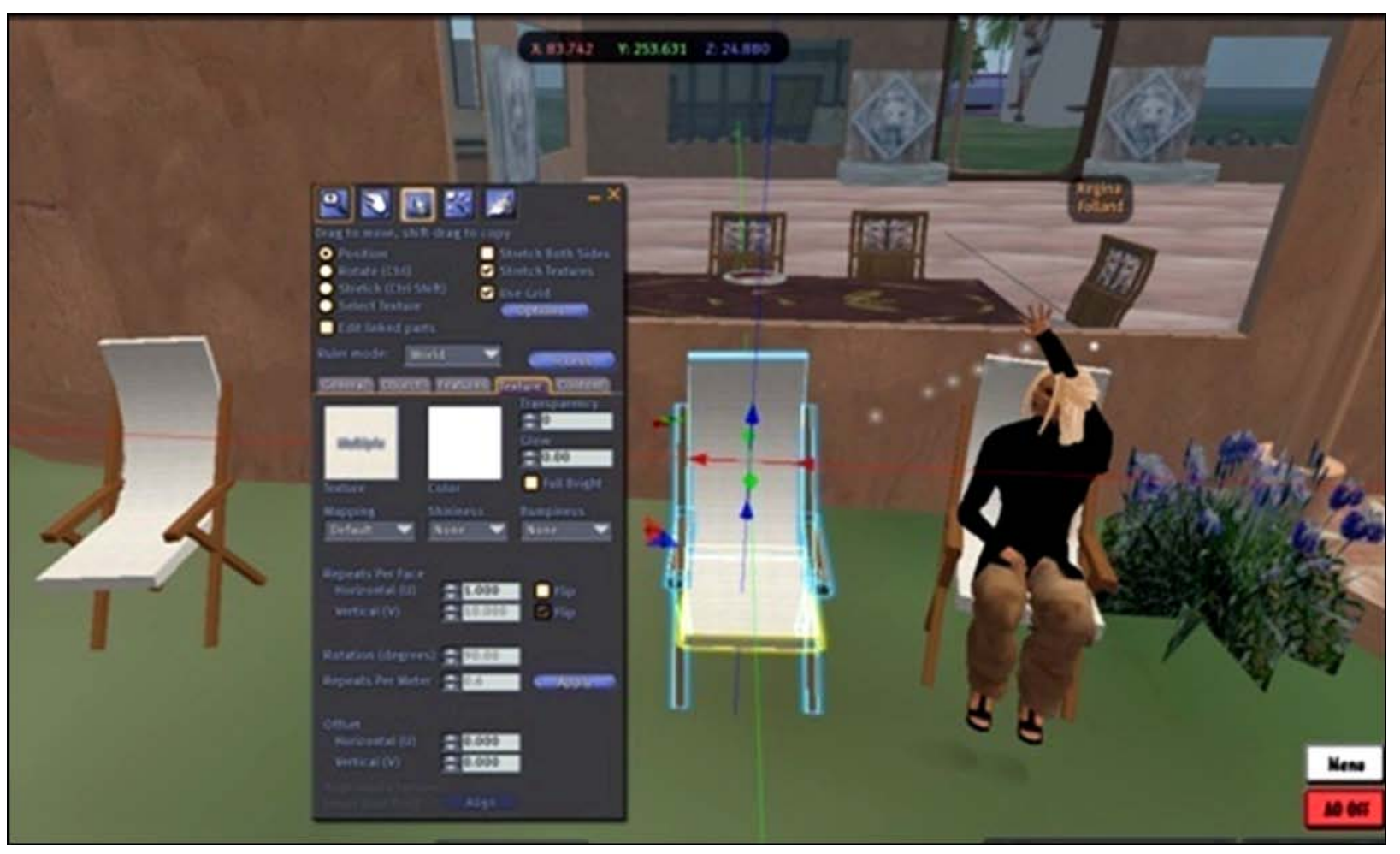

Figure 1. Regina creating (rezzing) a simple chair outside a restaurant. 
Every SL account holder has the prerogative to purchase land in the virtual world and to erect buildings on it. Large corporations (such as IBM) have created virtual headquarters and offices in SL to project their business presence in the virtual world, and to facilitate meetings without the need for physical travel. Universities and colleges (such as Princeton, Harvard, and Stanford) have likewise created virtual campuses in SL, and even hosted Campus Open Days to attract potential applicants. Many denizens of SL have even made a name for themselves by selling (virtual) merchandise, handicrafts, and fashionable clothing. There is even a virtual monetary exchange created for the purpose of trading the game money (Linden dollar) with real world currencies (see http://www.lindex.com), not to mention virtual solar systems, virtual museums, etc. Once again, these types of model building (or rezzing) were unheard of before the advent of game modification.

\section{MODIFYING GAMES FOR RESEARCH, DEVELOPMENT, AND LEARNING}

Once a non-word, the term "modding” (gamers' lingo for game modification) has increasingly been referred to in scholastic journals and gained acceptance by their international readerships. A quick search using Google Scholar (http://scholar.google.com) would easily reveal thousands of articles (mostly descriptive research) about why video games should be used to support learning. No doubt, most educators would already be familiar with the thesis put forth by serious game proponents, such as Prensky (2001) and Gee (2003). Since much has been written about the potential and advantages of digital games and/or game-related activities (including game modification) for learning - ranging from motivational factors, to authentic scenario-based learning, to a safe environment for dangerous activities - they will not be repeated here. We will, instead, turn to another important issue that has seldom been addressed.

\section{Who is doing what? Why?}

If the activities of game playing and game making are indeed good for learning, (based on the voluminous works arguing for the activity), shouldn't game modification, which is a very low cost game making process, be introduced to students and teachers as a viable classroom learning activity? Prensky (2008) argued that it would be the tech-savvy students who would master the game modding (and in turn, teach the teachers about it). As the digital natives are entering the teaching professions, we contend that they might turn the situation around, and begin to create game modules for instruction and classroom learning, and further, share the learning process with the rest of the learning community.

In just the last 5 years alone, a number of research and development works have been published that involved modding of COTS games and virtual environments. Examples include: Squire's doctoral dissertation based on Civilization III (2004), Barab and colleagues' work involving ActiveWorld (2005), Kadakia's research work using Morrowind (2005). The Neverwinter Nights game development kit (GDK) was one of the more popular GDK used by researchers and was mentioned in a number of research articles, including Gorniak and Roy (2005); Loh and Byun (2009); etc. Other educators have tested the effectiveness of instructional materials created using GDKs, for subjects such as history (Squire, 2004), narration and literacy (Robertson \& Good, 2005), journalism (Paul, Hansen \& Taylor, 2005), science education (Barab, Thomas, Dodge, Carteaux, \& Tuzun, 2005), and economics (Carbonaro, et al., 2005).

\section{Learning to Learn}

Since the mid 1980s, researchers such as Papert (1980, 1993), Kafai (1994, 1996, 1998), and Rieber (1996) have been working with children in using authoring software, such as Logo, Authorware, and Game Maker, to create games as a learning process. In other words, they regard game building (and modification) as a process of learning from a constructionist perspective. Constructionists believe that the process of learning may be defined through the very act of artifact construction (i.e., building/creating something as evidence of someone’s learning). 
Just like the taste and presentation of a dish directly reflects how good a chef is, the quality of the learning artifact (in this case, a playable game module instead of a dish) produced might also be used as a yardstick to measure the level of learning in the students. The learners would often go beyond the minimum requirement of learning the GDK, and in addition, engage in research about game design, scripting, programming, graphic editing, etc., in order to create a game module of which they would be proud. The quality of game modules produced could be raised even further when coupled with collaborative or competitive team works. Because the game making process might take several weeks or months to complete, this approach was best suited for after-school programs, or extra-curricular student societies.

Since game modification involves scripting and fairly complex technical skills, common wisdom suggests that a teacher who is well versed with the technical aspects of the GDK might be needed to provide guidance and assistance to the students. This might pose a problem for school teachers because many might hesitate to add to an already full plate, or to push aside anything in a tightly integrated curriculum. However, Prensky (2008) asserted that this was not a problem because many students were, in fact, more tech-savvy than their teachers. One student offered the following quip: "Don't try to use our technology, you'll only look stupid” (p.1005).

Certainly this should not be taken to mean that educators should avoid modding/rezzing (or technology), lest they appear "stupid" in the eyes of their students, should it? After all, many researchers mentioned in earlier sections had to learn how to create their unique research platforms by first learning to mod/rez, just like the rest of the gamers. As demonstrated by these researchers, both the process of modding and rezzing, as well as the product created, carried great educational potentials. In the following sections, we will examine how modding and rezzing can be used as learning processes and as tools for authoring new learning materials.

\section{Mind Tools}

The number of game authoring tools and GDKs available in the last five years has gradually increased. As more and more researchers began exploring GDKs as authoring tools to create new test-beds and environments for research, they have come to realize that GDKs can be viable tools for interactive learning development. As mentioned before, the first of its kind was MarineDoom, a game module developed by the U.S. Marines to train soldiers and marines in team work and cooperation.

From a mind tool perspective (Jonassen, 1996), GDKs for video games and the rezzing tool for SL are no different from slide presenters, Word Processors, or Web page editors, because they empower users to unlock what is in their minds and share representations of the "images/objects" with others. It is up to the researchers and educators to make use of these mind tools to author new interactive learning environments or instructional materials. Similarly, the students are free to express their mental images through storytelling using the GDKs, and to invite others to share a glimpse of their mental worlds by means of the rezzing tools.

\section{Validating Theories}

The growing trend of game modification has begun to attract the attention of researchers and educators. Besides research and development work made possible through game modification using GDKs, education researchers have also investigated the game modification process from the perspectives of contemporary learning theories. For example, using an instructivist's approach, Moshirnia (2007) conducted a study investigating the effectiveness of a modified game in helping 10th-12th graders comprehend and retain declarative knowledge of history. Findings were generally positive and showed 
the students to be able to retain and comprehend the learning materials. Furthermore, the students were motivated about "experiencing” the American Revolution via a Civilization IV game module.

Using a Collaborative (Social) learning approach, Steinkuehler \& Johnson (2009) argued that modding demonstrates and enhances deep computer literacy "in the contemporary participatory socio-technical world” (p.55). Their analysis of World of Warcraft (WoW) modding communities led to the conclusion that modding involved a highly collaborative environment and that "the days of the lone student working on computer code in isolation are outdated" (p.63). Consequently, modding was viewed as a collaborative and negotiated authorship, whose activities were goal-driven.

In addition to the instructivist and collaborative approaches, advocates of constructivism also have shown interest in game modification. Constructivism, which inspired constructionism, promotes the idea that learners actively construct their own learning and understanding through experience and reflection on that experience. Focusing on this philosophy, Robertson and Good (2005) allowed children to build their own game modules by letting them create plots and settings, as well as narratives. The result of this experiment showed the existence of beneficial effects related to the development of narrative stills and overall literacy, which constructively speaking, the children built for themselves.

Based on the example of the above-mentioned experiment, Steiner, Kaplan \& Moulthrop (2006) engaged in an analysis of the process with which their subjects created game plans and the games themselves. The focus of the analysis was on the participants' reflections on their experiences. The children made discoveries about their roles as builders and players, as well as about the differences between developers and players. These insights prompted the researchers to conclude that "both designing games and building them for themselves provide opportunities for learning problem-solving and teamwork” (p.140).

Educators should be flexible in adapting the process of modding into a learning situation. They should consider the process carefully from any number of theoretical perspectives before choosing one that is suitable for the class and the students. Learning could occur during the process of modding a game, or it could occur during the use of an educational game module. It is true that certain virtual environments may lend themselves more naturally to activities based on a particular theory of learning; and some game environments, such as first-person-shooters or war games, might be less appropriate for public school settings. But it is up to an innovative teacher to create the learning activities that best suit their students' learning abilities, based on the learning opportunities. A little creativity, coupled with the familiarity with the virtual environments, goes a long way.

\section{VIRTUAL ENVIRONMENTS: GAME WORLDS VS. VIRTUAL WORLDS}

Conceptually, a game world is a virtual environment created for one purpose: execution of the game story as conceived by the designer. When players "stepped into" the game world, they were temporarily transported into the game environment layout by the designer, to face whatever challenges were thrown at them. It would appear that the gaming activity tapped into the basic human desire to excel and overcome (both mental and physical) challenges laid before them, regardless of the form of the games: ball games, chess, maze, real-life battle, jig-saw puzzle, pen-and paper Dungeons and Dragons, obstacle course in military training, etc.

While the modification aspect might be similar, a virtual world (such as SL) does not have a grand scheme of (story) design to support its myriad activities. Despite the outward appearance of a game-like environment (i.e., buildings, roads, avatars), virtual worlds originated as 3D chat rooms and many still serve a primarily communicative purpose. However, a number of new features and plug-ins (such as video chat, and links to YouTube) that have recently been made available have transformed SL into something more. 
Today, virtual worlds are less like chat rooms, but more closely resemble news centers; they have become virtual spaces for interaction with information: reading text (e.g., books and web pages), listening to sound (audio books, MP3), or both (YouTube movies, band performance, virtual dancing). With some creativity, educators can take advantage of the multimedia display capability of these virtual environments and use them for teaching and instruction. For example, educators from the University of Minnesota have designed a story world and used it to teach journalism (Wong, 2007). This is very similar in concept to the SL blog (http://blog.secondlife.com) and SL newspapers (available at http://sl-newspaper.com). Educators should be interested to find a large number of education-oriented showcases in SL [visit http://secondlife.com/showcase/education/].

In summary, a virtual world can either be an application by itself (such as Google Earth) or a shell (or container) for other systems--be it macro (e.g., solar system), micro (e.g., cells/micro-organisms), dangerous historical events (war zones), or state of mind (e.g., Virtual Hallucination Lab in SL). Apparently, the possibilities are limited only by one's creativity. As more educators embrace the virtual worlds, they can begin to approach teaching in a different way, and not be limited by contents that are too dangerous (e.g. working in a chemical plant), too complex (e.g. working in a financial market), too expensive (e.g. going abroad to speak a foreign language with native speakers), or infeasible (e.g. traveling across the solar system). Readers who are interested in learning more about virtual worlds can find a comprehensive review at http://www.virtualworldsreview.com/info/categories.shtml. As technology continues to advance, it is foreseeable that the virtual world technology would gradually be morphed into 3D Internet browsers, such as 3DXplorer (http://www.3dxplorer.com), and 3B (http://www.3b.net).

\section{Non-Player Characters vs. Virtual People}

Besides the environment factors, it is just as important to remember who really makes up the avatars of the game worlds and virtual worlds. In a pre-designed game world, most of the characters are plot-related avatars, meaning they had been placed within the game deliberately by the game designer - even when they serve only as a "filler" to make an empty village look populated. When users interact with these avatars (or non-player characters, NPCs), the purpose is to elicit information from the NPCs in order to continue on the game quests. The responses from these NPCs have all been pre-written by script/story writers. Since the responses (behaviors) of these NPCs were determined by artificial intelligence, players of video games do not need to worry at all about hurting the NPCs feelings.

This is not so for virtual worlds because most avatars (virtual people) are made up of real people logging in from some more or less remote locations. Not only are the conversations spontaneous, these virtual people may even take offense when unkind words are spoken. While there is very little story telling within the virtual worlds, it may be more difficult to elicit information from virtual people than NPCs because it calls for (real) human interaction; even when the avatar you are speaking to may not appear human.

The MMOGs can be confusing because it looks and feels like a virtual world and yet operates using game mechanics. As the name suggests, an MMOG is a game that takes place in a massive virtual world. Hence, the narratives of MMOGs are very much driven by NPCs (more specifically, the Mission/Quest givers).

However, because of the sheer number of players in MMOGs - sometimes numbering in hundreds of thousands - the virtual environments can be intimidating to new players. To help players overcome the initial navigation confusion, game publishers have implemented quest journals/logs to help players keep track of their progress, and placed floating symbols above the head of Quest Givers to distinguish them 
from the sea of virtual people (Karlsen, 2008). In the MMOG convention, a floating exclamation point [!] would indicate the availability of a new quest; and upon completion of the quest, the [!] symbol would turn into a question mark [?] indicating that a reward is available for collection.

\section{PRACTICAL CONSIDERATIONS}

Educators interested in implementing game and virtual world modification in their instruction need to take several considerations into account - especially considerations relating to technological requirements and the instructional design approach used in developing game modules. The technological requirements would broadly include: hardware, software, network infrastructure, high-speed Internet connection (if the server is located remotely), space to house the equipment, technical support personnel, and amount funding available. Furthermore, teacher preparation, learning to use the GDKs and the games, modification of contents, and research overhead that goes into planning and creating the narratives, are but some of the factors that needed to be considered.

\section{Control for Undesirable Contents}

Even though there are many advantages in using virtual environment for teaching and instruction, teaching and instruction using virtual environments is still not suitable for students from all age groups at this moment. Because out-of-the-box virtual environments are created by game designers and not educators, there is very little control of the contents that are in video games or virtual worlds. Besides the issues of violence and gore in video games, which frequently make headlines of news and media, a more troubling issue is the nudity and sexual content that are present in video games and virtual worlds.

Because video games are commercial products, they are created with the intention to be profitable. Since an average video game buyer is a 35-39 year-old male (ESA, 2008, 2009), it should not be surprising that a large proportion of the full-feature and more successful games were targeted at this player group. This means that many of the top quality, best-selling games (with better graphics and narratives) may have content that is not suitable for students (under 17) in public schools. Besides the usual problems about gore and violence in these online games, there also exists another controversial content that is not currently rated by the Entertainment Rating System Board (ESRB): same sex encounters. For example, The Temple of Elemental Evil, a game published in 2003 by Troika Games, and reputably "the first mainstream videogame to promote gay marriages" (Barton, 2004), received only a Teen rating from the ESRB (US)! Based on the ESRB rating scheme, a "Mature” rating only identify the game as containing sexual theme, but failed to distinguish between hetero- and homosexuality. This explained why some countries in the world that allowed "M" rated games, singled out and banned Mass Effects (2007) because it contained a homosexual (lesbian) romance sub-plot.

Since majority of the subscription-paying players of MMOGs (e.g., WoW) and virtual worlds (e.g., SL) are adults, they are less likely to be bothered by the use of profanity or the display of partial to full nudity. Sometimes, unsuspecting players may stumble upon "tea parties" (gathering of large group of players) with the purpose of protesting "unfair treatment" or poor maintenance practice to the authority (i.e., the game publisher/developers). While peaceful demonstration is acceptable, in their attempt to attract as much attention as possible to their plight, these "tea parties goers" would often show up in (semi-)nudity! Educators using virtual environments for teaching and instruction may, unwittingly, find themselves in the middle of a tea party (Figure 2, color version available at http://www.csloh.com/research/book_chapter_images/), which can result in some serious explanation to the parents or school administrators! 


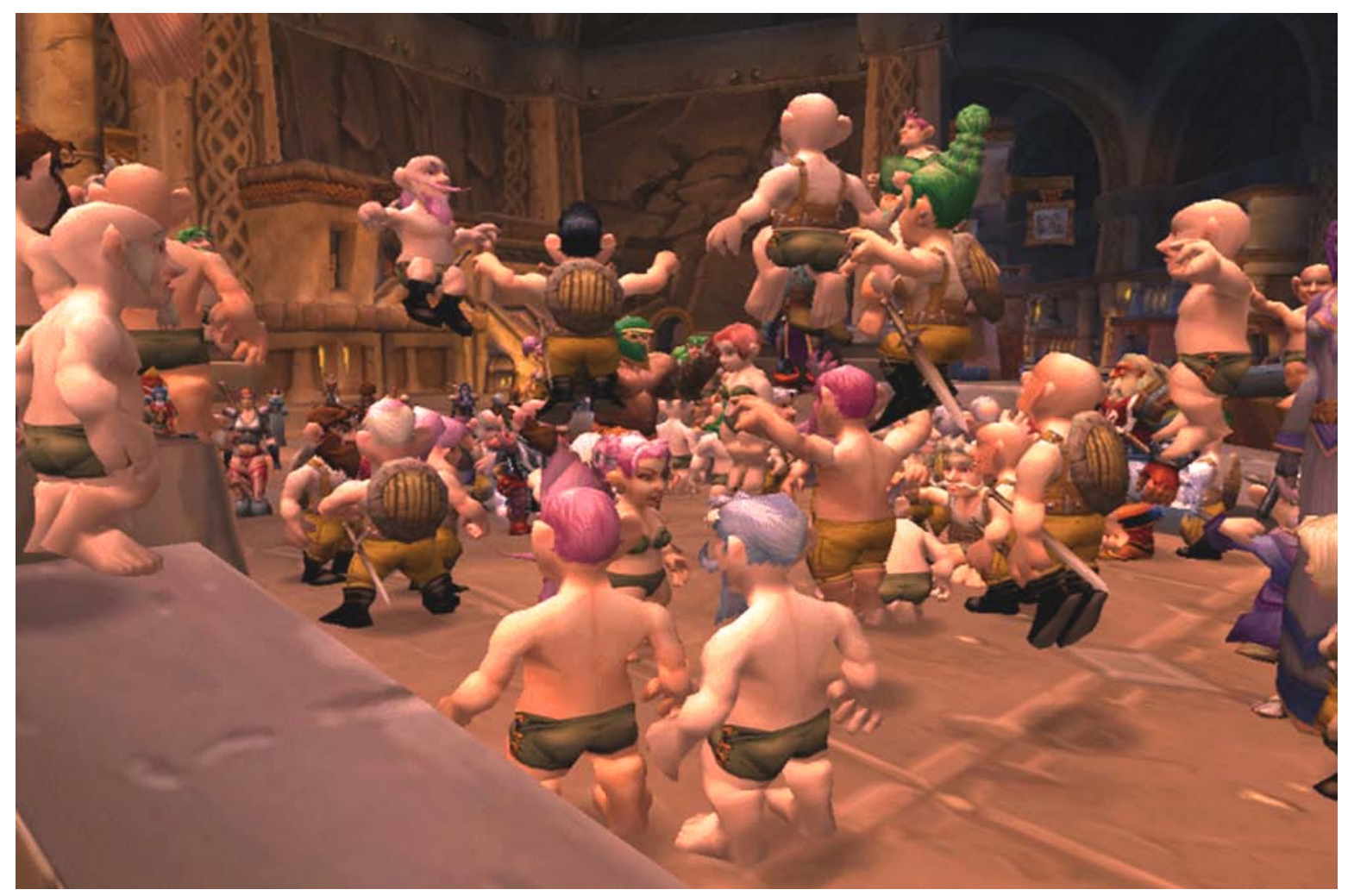

Figure 1: A Tea-Party held in World of Warcraft to protest about the weak Warrior class.

The dress code for the day was "gnomes in semi-nudity."

[No copyright, a screenshot of a historical event that took place in WoW.]

This means that before MMOGs and virtual worlds can be considered for teaching and learning, consideration must first be given to protect educators, students, and users from other cultures (and countries) who may be offended by the depiction of violence, gore, profanity, witchcrafts, and same sex relationship/marriage.

\section{The Need for Teacher Control}

Due to the issues mentioned above, it can be seen that teacher control will remain an important contention if virtual environments are to be used more widely for teaching and instruction. Likewise, the concern for undesirable content is not merely limited to the United States but is a global concern, in particular, to the more conservative countries. Public school teachers need to protect their students and avert them from unsavory imagery and potentially harmful situations, and must have the ability to control the contents being shown in the virtual environments.

In SL, the problem can be overcome partially by purchasing private land usually in the form of islands. Since the islands can be made private (i.e., accessible only by the owners and their invited guests) or semi-private (i.e., open to visitors, but with the owner of the land retaining the rights to banish misbehaving visitors), some levels of control can be maintained. The owner may further impose what activities - which include rezzing and flying - are permissible on their properties, in an effort to reduce the amount of distractions during lessons. Nevertheless, as land ownership in SL can be a costly affair, it is questionable as to how many public school districts would be willing to fund this option in the foreseeable future. 
Unfortunately, the option to purchase private land is not available in MMOGs at all. Furthermore, it is not possible to assert any form of control over the contents therein because the game servers are centrally maintained by the game publishers. Unless open source MMOG servers become available to allow for third-party content contribution, it is unclear if teacher-controlled contents will ever be possible. New business models may need to be formulated to include the option for teacher-created, or teachercontrolled, contents, with some kind of subscription scheme at the school or district level. The subscriptions may then be used by the game publishers to hire the personnel needed to create new game narratives, and provide teacher-control support.

The last viable option would be for teachers to learn how to modify COTS games and create "clean" contents that are suitable for teaching and instruction. Moreover, they should look into using only COTS games that came with dedicated servers, in order to maintain full control over user access. These schoolhosted (game) servers would then serve as virtual learning environments containing teacher- or studentcreated interactive learning contents. Once the game modification process is under the control of teacherdesigners, or teacher guided student-designers, undesirable content would become a non-issue, leaving the teachers to focus fully on teaching and instruction. Examples of COTS games that come with dedicated server services include Neverwinter Nights, Half-Life 2, and local area network (LAN) first person shooters.

\section{Scripting (Programming)}

Arguably, the most difficult task in a game modification process is that of scripting. Since NPCs were nothing more than animated 3D models, the game engines need to execute the animation only at the right moment; for example, animate a "sit" action, when the command "sit" were given. Unfortunately, game engines only communicate in programming language, and hence, scripting was needed to bridge the gap. Fortunately, game developers recognized that not everyone who is interested in game modding has a degree in Computer Science. Instead of forcing non-programmers (majority of modders) to manipulate the 3D models using programming language (such as Java or $\mathrm{C}++$ ), game developers created scripts (simplified programming codes that resembled human language) to make life easier for the gamers/modders. The following are examples of scripts used in NWN, and SL, respectively.

\section{Example 1 (NWN):}

The following NWN script instructs an NPC object, known as "Sophia" to perform a "Sit" action on an object called CHAIR.

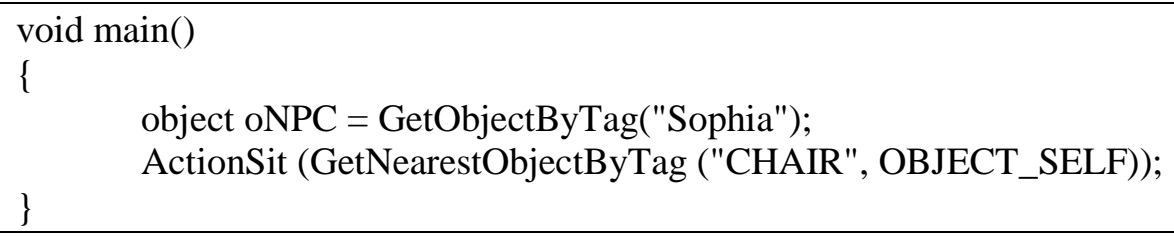

Example 2 (SL):

The SL script given below can be used to label objects with a desired text. In this case the label says "I am a floating text" with the position of this text given by the coordinates that follow. 


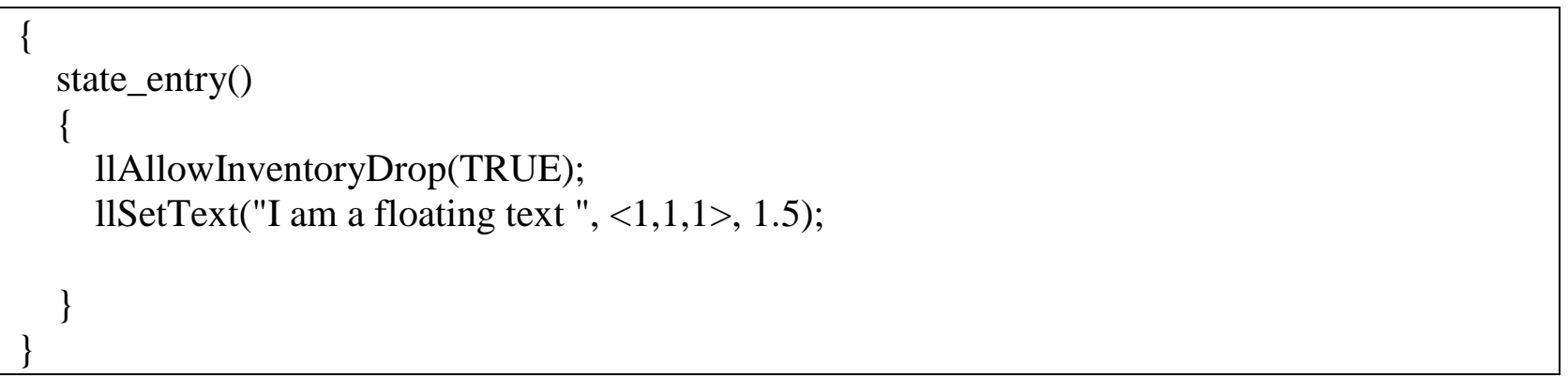

\section{Frequency of Patch and Application Update}

Another important factor for consideration when using virtual worlds for teaching and instruction can be the frequency of software update. Because of the size of the (software) program, a virtual environment application is usually divided into two portions: the server-side and client-side applications. Whenever the server-side application experiences an update, the client-side must also be updated in order to be compatible. Hence, whenever new bugs or problems arise and are fixed on the server-side application, the client-side must also be patched, or updated. At launch, the client-side would check online with the server to ensure the version number is compatible (or the same), before the client-side application would run.

Because so many people use SL, the server is under constant attack from hackers and must be updated frequently for security. Unfortunately, this means the client-side application must undergo just as many updates as the server-side: up to several times per week. Teachers who use SL for teaching and instruction until spring 2009 had to take on the additional burden to check for updates before conducting a lesson because the client-side application (so called, Second Life viewer) will not function properly until it has finished updating itself. Imagine a situation when the lesson is about to start and the teacher finds out at the last minute that SL has just released a new update which must be downloaded by every computer used in the classroom! The same situation would also apply to MMOGs.

The COTS modifiable video games (such as Neverwinter Nights and Half-Life 2) also have frequent updates, but they use a different update strategy: "pull” and not "push." This means that the update does not happen automatically (push), but is initiated on-demand by the users (pull). Hence, a teacher who discovers that an online game server needs to be updated, may do so after his/her lesson is completed, or schedule the update over the weekends, without being forced into any surprises.

\section{Choice of Virtual Environments}

Teachers who are interested in using a virtual environment for instruction need to spend time exploring the 3D modeling resources and learn how to modify the game resources using the toolkit provided. For example, if the courses were about language usage, a first person shooter game that allowed very little conversation between players and NPCs would not be useful. Likewise, virtual worlds with a futuristic setting would not be useful in teaching about the American Revolution or the Roman Empire. But above all, teachers' familiarity with the virtual worlds/video games and the development toolkit is of utmost importance because no content could be made without first learning how to use the toolkit; and not before learning how the game mechanics work.

Out of more than 30 virtual worlds available (as of 2009), each has something unique to offer. The choice of the virtual world used would depend on the themes, the budget available, the age group of the target audience, and even the speed of the Internet connection available. For example, elementary and middle school teachers could consider using Disney Toontown (http://www.toontown.com) or Teen Second Life (http://www.teensecondlife.com), which target at the respective age group. However, the authors believe that in the near future, more user-friendly GDKs will be made available to help teachers develop new 
virtual worlds suitable for classroom teaching and learning. Once the appropriate business model is found, game (or virtual learning) companies would begin working with school districts to create virtual environment servers for the hosting of template-based virtual interactive learning modules that are created by both teachers and students.

\section{Instructional Development \& Performance Assessment}

No matter who would develop the interactive learning modules, it is crucial for some kind of instructional design underpinnings to be implemented during the development of the instructional resources or learning modules. For instance, even though Rapid Prototyping development model was originally proposed for computer application and engineering process (Dey, Abowd, \& Salber, 2001; Jones \& Richey, 2000), it has been successfully adapted for the development of interactive learning (game) modules by Loh and Byun (2009). Likewise, the well-known instructional design processes comprised of: Analysis, Design, Development, Implementation, Evaluation - collectively known as the ADDIE Model (Dick \& Carey, 1996; Leshin, Pollock, \& Reigeluth, 1992) - have also been suggested to be a possible model for serious games development (Byers, 2009).

Last but not least, assessment of what the learners do in the virtual environment is also important to educators. Although most of the research for the moment has been focused on the potential of game-like environment (e.g., Warren, 2007; Young, Schrader, \& Zheng, 2006) and independent development processes (e.g., Quinn, 2005; Reese, 2007), a few researchers have begun looking into new methods of assessing learners' performance within game worlds and virtual environments (Loh, Anantachai, Byun \& Lenox, 2007; Reese, 2008).

\section{CONCLUSIONS}

Virtual environments such as those commonly found in game and virtual worlds are becoming increasingly common. Many users have learned to create new content through modification using GDKs and 3D modeling tools available at a very low cost. These authoring tools allow users to quickly create a playable and traversable environment using ready-made resources, such as environmental sounds (birds chirps, water dripping, waves), 3D models (tables, containers, trees, buildings, humanoids, animals), and area templates (arctic, desserts, jungle, tundra, bottom of sea). The availability of such templates makes it easy for gamers to create virtual areas with fine details and movable props. It also lowers the technical requirements so that even teachers and students are able to learn the GDK in a short time - making the game modification process viable for classroom (and after-school) use.

Although Star Trek's Holodeck is still unattainable with today's technology, and must continue to reside in the imagination of visionaries and the silver screens (as well as in SL), the ability to create virtual environments for teaching and instruction is now possible. With some creativity and time to spare, earlyadopter teachers can have a technology in their hands that will allow them to deliver classroom instruction in a whole new way that is motivating, innovative, and literally "out of this world." Instead of letting the students while away their time aimlessly on videogames, MMOGs and virtual worlds, the time has come for teachers to use the technology the students so love in a positive manner for teaching and instruction.

"Come, the game is afoot." 


\section{REFERENCES}

Barab, S., Thomas, M., Dodge, T., Carteaux, R., \& Tuzun, H. (2005). Making learning fun: Quest Atlantis, a game without guns. Educational Technology, Research, and Development, 53(1), 86-107.

Barton, M. D. (2004, March). Gay characters in videogames. Armchair Arcade. Retrieved April 10, 2008, from http://www.armchairarcade.com/neo/node/305

Becker, K., \& Parker, J. R. (2005, Oct 13-15). All I ever needed to know about programming, I learned from re-writing classic arcade games. Paper presented at the Future Play: The International Conference on the Future of Game Design and Technology, East Lansing, MI.

Berger, A. (2006, January 31). Neverwinter Nights in the Classroom. University of Minnesota News. Retrieved April 30, 2008, from

http://www1.umn.edu/umnnews/Feature_Stories/22Neverwinter_Nights22_in_the_classroom.html

Byers, C. (2009). Digital simulations for improving education In D. Gibson \& Y. K. Baek (Eds.), Digital simulations for improving education: Learning through artificial teaching environments. Hershey, PA: Information Science Reference.

Carbonaro, M., Cutumisu, M., McNaughton, M., Onuczko, C., Roy, T., Schaeffer, J., Szafron, D., Gillis, S., \& Kratchmer, S. (2005). Interactive story writing in the classroom: Using computer games. Paper presented at the DiGRA 2005 Conference, Vancouver, Canada.

Dey, A. K., Abowd, G. D., \& Salber, D. (2001). A conceptual framework and a toolkit for supporting the rapid prototyping of context-aware applications. Human-Computer Interaction, 16 (2-4), 97-166.

Dick, W., \& Carey, L. (1996). The systematic design of instruction $\left(4^{\text {th }}\right.$ ed.). New York, NY: Harper Collins College Publishers.

ESA (2008). Essential facts about the computer and video game industry. Washington, DC:

Entertainment Software Association. Retrieved Aug 1, 2008 from

http://www.theesa.com/facts/pdfs/ESA_EF_2008.pdf

ESA (2009). Essential facts about the computer and video game industry. Washington, DC:

Entertainment Software Association. Retrieved Aug 1, 2009 from

http://www.theesa.com/facts/pdfs/ESA_EF_2009.pdf

Gee, J. P. (2003). What video games have to teach us about learning and literacy ( $2^{\text {nd }}$ ed.). New York: Palgrave Macmillan.

Gee, J. P. (2008). Learning and Games. In K. Salen (Ed.), The ecology of games: Connecting youth, games, and learning (pp. 21-40). Cambridge, MA: The MIT Press.

Gorniak, P., \& Roy, D. (2005). Speaking with your sidekick: Understanding situated speech in computer role playing games. Paper presented at the 1st Artificial Intelligence and Interactive Digital Entertainment Conference (AIIDE). Retrieved April 10, 2008, from

http://petergorniak.org/papers/AIIDE05GorniakSituatedSpeech.pdf

Jonassen, D. H. (1996). Computers in the classroom: Mindtools for critical thinking. Merrill: Englewood Cliffs, N.J. 
Jones, T. S., \& Richey, R. C. (2000). Rapid prototyping methodology in action: A developmental study. Educational Technology Research and Development, 48 (2), 63-80.

Kadakia, M. (2005). Increasing student engagement by using Morrowind to analyze choices and consequences. TechTrends, 49 (5), 29-32.

Kafai, Y. B. (1994). Electronic play worlds: Children's construction of video games. In Y. B. Kafai \& M. Resnick (Eds.), Constructionism in practice: Rethinking the roles of technology in learning (pp. 97-123). Mahwah, NJ: Lawrence Erlbaum Associates.

Kafai, Y. B. (1998). Video game designs by girls and boys: Variability and consistency of gender differences. In J. Cassell \& H. Jenkins (Eds.), From Barbie to Mortal Kombat: Gender and computer games (pp. 90-117). Cambridge, MA: MIT Press.

Kafai, Y. B. (2006). Playing and making games for learning: Instructionist and constructionist perspectives for game studies. Games and Culture, 1 (1), 36-40.

Kafai, Y. B., \& Resnick, M. (Eds.). (1996). Constructionism in practice: Designing, thinking, and learning in a digital world. Mahwah, NJ: Lawrence Erlbaum Associates.

Karlsen, F. (2008). Quests in context: A comparative analysis of Discworld and World of Warcraft. Game Studies, 8 (1).

Leshin, C. B., Pollock, J., \& Reigeluth, C. M. (1992). Instructional design strategies and tactics. Englewood Cliffs, NJ: Education Technology Publications.

Loh, C. S., Anantachai, A., Byun, J., \& Lenox, J. (2007). Assessing what players learned in serious games: in situ data collection, information trails, and quantitative analysis. In Q. Mehdi (Ed.), Computer games: AI, animation, mobile, educational \& serious games (CGAMES). Wolverhampton, UK: University of Wolverhampton.

Loh, C. S., \& Byun, J. H. (2009). Modding Neverwinter Nights into serious games. In D. Gibson \& Y. K. Baek (Eds.), Digital simulations for improving education: Learning through artificial teaching environments (pp. 408-426). Hershey, PA: Information Science Reference.

Lowood, H. (2008). Found technology: Players as innovators in the making of machinima. In T. McPherson (Ed.), Digital Youth, Innovation, and the Unexpected (pp. 165-196). Cambridge, MA: The MIT Press.

McLeroy, C. (2008, September). History of Military Gaming. Soldiers, 63, 4-6.

Moshirnia, A. (2007). The educational potential of modified video games. Issues in Informing Science and Information Technology, 4, 511-521.

Papert, S. (1980). Midstorms. New York, NY: Basic Books.

Papert, S. (1993). The Children's Machine. New York, NY: Basic Books.

Partnership for 21st Century Skills (2006). Results that matter: 21st century skills and high school reform. Tucson, AZ: Partnership for 21st Century Skills. 
Paul, N., Hansen, K., \& Taylor, M. (2005) Modding Neverwinter Nights: A simulation for reinforcing information seeking concepts for Mass Communication students. Paper presented at the DiGRA 2005 Conference, Vancouver, Canada.

Prensky, M. (2001). Digital game-based learning. New York, NY: McGraw Hill.

Prensky, M. (2008). Students as designers and creators of educational computer games: Who else? British Journal of Educational Technology, 39 (6), 1004-1019.

Reese, D. D. (2007, March 23-27). Designing Selene: Theory-based game design and data-mining. Paper presented at the Serious Games Summit, San Francisco, CA.

Reese, D. D. (2008). Engineering instructional metaphors within virtual environments to enhance visualization. In J. K. Gilbert, M. Reiner \& M. Nakhleh (Eds.), Visualization: Theory and practice in science education (Vol. 3) (pp. 133-153). Springer Netherlands.

Rieber, L. P. (1996). Seriously considering play: Designing interactive learning environments based on the blending of microworlds, simulations, and games. Educational Technology, Research, and Development, 44 (2), 43-58.

Robertson, J., \& Good, J. (2005). Story creation in virtual game worlds. Communications of the ACM, $48(1), 61-65$.

Squire, K. (2004). Replaying history: Learning world history through playing Civilization III. Unpublished Doctoral Dissertation, Indiana University, Bloomington, IN.

Steiner, B., Kaplan, N., \& Moulthrop, S. (2006). When play works: Turning game-playing into learning. Paper presented at the 2006 Conference on Interaction Design and Children, Tampere, Finland.

Steinkuehler, C., \& Johnson, B. Z. (2009). Computational Literacy in Online Games: The Social Life of Mods. International Journal of Gaming and Computer Mediated Simulations, 1 (1), 53-65.

Wong, W. (2007, May/June). Gaming In Education. Ed Tech Magazine. Retrieved April 10, 2008 from http://www.edtechmag.com/higher/may-june-2007/gaming-in-education.html

Young, M. E., \& Nguyen, N. (2009). The problem of delayed causation in a video game: Constant, varied, and filled delays. Learning and Motivation. 40 (3): 298-312.

Young, M., Schrader, P. G., \& Zheng, D. P. (2006). MMOGs as learning environments: An ecological journey into Quest Atlantis and The Sims Online. Innovate: Journal of Online Education, 2 (4).

\section{KEY TERMS}

COTS game: commercial, off-the-shelf game, made by game publishers for profit.

Game Development Kit (GDK): A toolset that is often bundled with a COTS game, usually with the sanction from the publishers, for the purpose of creating new content by the players. 
Machinima: short for machine cinema: a movie created through screen capturing of a game mod in play, and voiced over in order to 'tell' a story.

Mod: short for game module. A game created using GDK, requires preinstalled game engine to play.

Modding: from modifying, creating game modules (mods) with a GDK.

Rezzing: creating or making objects to appear in a virtual world, especially in Second Life.

Virtual Environment: an interactive digital environment created with computer/digital graphics, commonly found in today's video games (including Massive Multiuser online games, or MMOGs), and virtual worlds (such as Second Life). 